\title{
Instruction-dependent facilitation during a pretimeout stimulus in human subjects*
}

\author{
R. E. REMINGTON and K. T. STRONGMAN \\ University of Exeter, Exeter, Devon, England
}

Two groups of human Ss were run for monetary reward in baseline and test conditions using timeout (TO) as a US in a CER paradigm. Groups differed only with respect to experimental instructions. The $\mathrm{F}$ group received instructions which established the TO discrimination, whereas the $\mathbf{R}$ group received similar instructions which did not. A facilitatory effect during CS in the test phase was found to be mainly a function of those instructions which did not specify the significance of the TO stimulus.

A stimulus signaling timeout from positive reinforcement (TO) on partial-reinforcement schedules has been shown to cause response facilitation in chimpanzees (Ferster, 1958) and pigeons (Leitenberg, 1966), while causing response suppression in rats (Leitenberg, Bertsch, \& Coughlin, 1968). Fenholme, Baron, \& Kaufman (1969) have demonstrated that signaled TO produces response facilitation during the signal (CS) in human Ss. Their procedure allowed a long period of baseline training (CS alone), initially on a schedule which differentially reinforced a low rate of responding (DRL 20-sec), and later on a variable interval schedule (VI 1.33-min) with a concurrent DRL 5-sec. Pairings of $\mathrm{CS}$ and TO were extended over 12 50-min sessions, but the effects of the original DRL contingency on overall response rate caused any response facilitation to be associated with a greater frequency of reinforcement, thus unfortunately obscuring interpretation.

The present study was designed in an attempt to compress the procedure of Trenholme et al while removing the possibility of increased reinforcement frequency during any $\mathrm{CS}$ facilitation. In order to assess the effects of contiguity of $\mathrm{CS}$ and TO, the control procedure described by Rescorla (1967) was employed. Where a $\mathrm{S}$ does not experience both kinds of stimuli during prior baseline conditions, it is possible that the effects found during a test phase are due solely to the introduction of $\mathrm{TO}$, rather that to its contiguity with the CS. A further aim of the present experiment was to test the relevance of experimental instructions in this situation.

\section{SUBJECTS AND APPARATUS}

Twelve male college students were paid for a $2-h$ session on the basis of their performance at the task. Ss sat individually at a table in a sound-attenuated room

*This study was supported by Medical Research Council Grants G967/271/B and G969/267/B to the second author. facing a $20-\mathrm{cm}$ lever mounted vertically in a rectangular case. The lever served as a manipulandum. A response was defined as the displacement of the lever from its vertical resting position through $50 \mathrm{deg}$ toward the $S$ and back again. Behind the lever, easily visible to the $S$, was a stimulus panel which displayed an impulse counter, a red light, and two green lights. Concealed behind this panel was a clicker, which operated when a response was made, and a buzzer, which served as a CS.

\section{INSTRUCTIONS}

Typed instructions were left in the test room throughout the session. One group of six Ss ( $F$ group) received the following instructions:

"If you pull the lever while the green lights are on, you can score points on the counter. Every time you score a point you have earned $1 \frac{1}{2} \mathrm{~d}$, and you will be paid according to the number of points you have scored at the end of the session. When you score a point on the counter, the red light flashes on and off to signal that you have scored.

"You are free to do what you want for the whole session, but you will have to work in order to earn points (i.e., money). If you do not pull the lever at all, you will earn nothing; so, if you're interested in earning money, it will be worth your while to stay alert and respond.

"You cannot score points unless you are making complete responses. To help you do this, you will hear a distinct click each time you move the lever from A to B and back again. When you hear this click, it means that you are responding correctly.

"At certain times, you may hear a quiet buzzing sound.

"You cannot score points if the green lights are out.

"If you earn more than 22/6d (180 points) in the time available, you will have the opportunity to take part in a similar experiment in which you could earn up to $£ 4$ in two 2 -h sessions. (Times to be arranged at the end of the session).
"Read this through as many times as you wish, but please do not ask any questions."

Thus, the F group received full instructions establishing the discrimination between timeout and "normal time."

For the group of six Ss with reduced instructions ( $R$ group), the first set of italicized words was omitted, and the second set was replaced by the sentence: "Similarly, at certain times the green lights may go out." (Italics did not, of course, appear in the instructions for either group.)

The purpose of the penultimate paragraph of the instructions was to maintain motivation throughout the task. The experimental conditions were in fact such that Ss could earn a maximum of 160 points.

BASELINE TRAINING

Each $S$ was seated in the experimental room and allowed to read the relevant instruction sheet. Apart from this, Ss in the $F$ and $R$ groups received the same experimental treatment.

The session began with a $32-\mathrm{min}$ baseline period, during which Ss responded on a VI 30-sec schedule with a limited hold (LH) contingency of $5 \mathrm{sec}$. The baseline incorporated a Rescorla proper control procedure for classical conditioning by which CS and TO were each presented randomly and independently seven times. Thus, all Ss had experienced CS and TO before the onset of the test phase.

SIGNALED TIMEOUT

Following baseline training, Ss received 17 pairings of $\mathrm{CS}$ and TO, randomly spaced over $118 \mathrm{~min}$. In both conditions the CS consisted of the operation of the buzzer for $30 \mathrm{sec}$, while the 100 -sec duration of TO was signalled by the offset of the green lights.

During all phases of the procedure, the response rate during each presentation of $\mathrm{CS}$ and TO was recorded, together with the rate in the $30 \mathrm{sec}$ directly preceding the $\mathrm{CS}$ (PCS time).

\section{RESULTS}

The extent to which facilitation occurred during the CS was calculated using a modification of the conventional suppression ratio. Here, facilitation was calculated from an $\mathrm{f}$ score where:

$$
\mathrm{f}=100\left[1+\left(\frac{\mathrm{RCS}_{\mathrm{i}}-\mathrm{RPCS}_{\mathrm{i}}}{\mathrm{RCS}_{\mathrm{i}}}\right)\right] \%
$$

where $\mathrm{RCS}_{\mathrm{i}}$ and $\mathrm{RPCS}_{\mathrm{i}}$ were the total responses in the $i^{\text {th }}$ presentation of the $C S$ and PCS, respectively $(i=1,2, \bullet \bullet, 24)$. Thus, if there were no effect of CS condition, $\mathrm{f}=100 \%$, whereas a facilitation would yield $\mathrm{f}>100 \%$ and a suppression, $\mathrm{f}<100 \%$. This score was computed for 
Table 1

f Scores, Response Rates, and Reinforcements for Individual Si

\begin{tabular}{|c|c|c|c|c|c|c|}
\hline$S$ & GRP & $\begin{array}{l}\text { Median } \\
\text { Base- } \\
\text { line } \\
t\end{array}$ & $\begin{array}{l}\text { Median } \\
\text { Text } \\
t\end{array}$ & $\begin{array}{l}\text { Hean } \\
\text { Response } \\
\text { Rate in } \\
\text { TO }\end{array}$ & $\begin{array}{c}\text { Mcan } \\
\text { Rcypome } \\
\text { Rate in } \\
\text { "Normal I ime" }\end{array}$ & $\begin{array}{l}\text { Total } \\
\text { Reintorec- } \\
\text { ment } \\
\text { Obtained }\end{array}$ \\
\hline 1 & 1: & 93 & 100 & 0.42 & 46.9 & 147 \\
\hline 2 & $\mathrm{I}:$ & 118 & 110 & 1.85 & 41.2 & 152 \\
\hline 3 & $1:$ & 99 & 95 & 0.30 & 37.6 & 148 \\
\hline 4 & 1: & 100 & 111 & 0.43 & 33.5 & 148 \\
\hline 5 & $1:$ & 100 & 110 & 6.13 & 60.4 & 139 \\
\hline 6 & $1:$ & 102 & 100 & 0.43 & 17.4 & 146 \\
\hline 7 & $\mathrm{R}$ & 131 & 150 & 5.03 & 6.3 & 140 \\
\hline 8 & $\mathrm{R}$ & 111 & 118 & 4.35 & 47.2 & 144 \\
\hline 9 & $\mathrm{R}$ & 78 & 104 & 5.05 & 21.1 & 139 \\
\hline 10 & $\mathrm{R}$ & 100 & 105 & 10.65 & 51.7 & 157 \\
\hline 11 & $\mathrm{R}$ & 102 & 104 & 85.38 & 139.5 & 160 \\
\hline 12 & $\mathrm{R}$ & 103 & 102 & 33.73 & 91.2 & 160 \\
\hline
\end{tabular}

every PCS/CS presentation for each S; the median f scores during baseline and test, again for each $\mathrm{S}$, appear in Table 1 .

Median f scores in baseline and test were compared for all $12 \mathrm{Ss}$ using a Wilcoxon t test (Siegel, 1956) since inspection showed that the data was not normally distributed. There was a significant facilitation during the CS under the experimental, TO, condition $(\mathrm{p}<.05$, $t=15.5$, one-tailed). However, the difference between the baseline and test scores for the $F$ group alone was not significant $(p>05, t=7)$, whereas the facilitatory effect remained significant for the $\mathrm{R}$ group taken alone $(\mathrm{p}<.05,1=1)$. It was concluded that the effect of the CS on response rate was largely neutralized by the effect of full instructions. Also, since all Ss obtained virtually the maxinum number of points (see Table 1), the effect was unlikely to be due to adventitious reinforcement.

Mean response rates during periods where TO was not in effect (normal time) were compared for $F$ and $R$ groups using a Mann-Whitney U test (Siegel, 1956), but no significant difference was found $(\mathrm{U}=13, \mathrm{p}>.05)$. However, using the same test, the rate during TO for the $\mathrm{R}$ group was significantly higher than that for the $F$ group receiving instructions that discriminated TO from normal time $(\mathrm{U}=3$, $\mathrm{p}<.01)$. Despite this, comparing mean TO and normal time rates for both groups separately yielded significantly lower rates in TO ( $\mathrm{F}$ and $\mathrm{R}$ groups: $\mathrm{t}=0, \mathrm{p}<.05)$. For $\mathrm{Ss}$ in the $\mathrm{F}$ group, cumulative records were virtually flat from the start of the session, whereas $\mathrm{Ss}$ in the $\mathrm{R}$ group gradually reduced their rates as the session progressed. Differences in this group between total responses in the first and last six TO periods were found to be significant $(\mathrm{t}=0, \mathrm{p}<.025$, one-tailed $)$.

\section{DISCUSSION}

The results partially confirm the finding of Trenholme et al that a facilitatory effect during a CS can be obtained using TO as a US in a CER paradigm with human Ss. In the comparatively compressed experimental design used in the present study, the effect was found to be small but significant. Further, it was also found to be present where Ss did not increase their probability of reinforcement by responding at a higher rate. In contradiction to the earlier finding, instructions establishing the discrimination of TO had the effect of neutralizing the facilitation found when instructions were omitted, although noninstructed Ss had clearly shown evidence of learning the discrimination by the end of the session.

Analysis showed that (1) where the TO discrimination was immediately learned, as for $\mathrm{F}$ group Ss, there was no effect; and (2) Ss in the $R$ group had learned the discrimination within 24 presentations of TO. It may therefore be concluded that the CS facilitatory effect is transitory in quality of speech in voting for leaders. inuman Ss using small amounts of money as a reinforcer. Trenholme et al, however, have shown a relatively stable effect.

If the immediate effect of a CS signaling TO, regardless of instructions, is facilitatory and if in turn this faster response rate leads to increased reinforcement density, the effect may be fortuitously maintained. In the present study, where this did not occur, the effect was relatively transitory, producing an insignificant effect in instructed Ss and a small, but significant, effect in Ss receiving no instructions.

At present it would scem unlikely that. with human Ss working at a simple task, a durable emotional effect could be obtained. This is especially true where only small monetary rewards, mildly aversive unconditioned stimuli and unrealistic experimental situations are employed.

\section{REFERENCFS}

FERSTER, C. B. Control of behavior in chimpanzees and pigeons by time out from positive reinforcement. Psychological Monographs, 1958, 72(8, Whole No. 461).

LEITENBERG, $\mathrm{H}$. Conditioned acceleration and conditioned suppression in pigeons. Journal of the Experimental Analysis of Behavior. 1966. 9. 205-212.

LEITENBERG, H., BERTSCH, G., \& COUGLIN, R. "Time-out from positive reinforcement" as the UCS in a CER paradigm with rats. Psychonomic Science, 1968, 13, 3-4.

RESCORLA, R. Pavlovian conditioning and its proper control procedures. Psychological Review, 1967, 74, 71-80.

SIEGEL, S. Nonparametric statistics. New York: McGraw-Hill, 1956.

TRENHOLME, I., BARON, A., \& KAUFMAN, A. Effects of signaled time-out from and loss of monetary reinforcement on human operant behavior. Psychonomic Science, 1969. 15 295-296.

\title{
Leadership selection under differing feedback conditions
}

\author{
CABOT L. JAFFEE, ${ }^{*}$ STEVEN A. RICHARDS, ${ }^{* *}$ and GERALD W. McLAUGHLIN ${ }^{\dagger}$ \\ University of Tennessee, Knoxville, Tenn. 37916
}

Under two differing feedback conditions (specific and nonspecific) leadership voting within small groups was analyzed. It was found that modifying the percentage of reinforcement to different Ss influenced voting behavior significantly, and that Ss in the two treatment conditions did not differ in their ability to match votes with reinforcements. It was felt that Ss respond more rapidly to duration of speech rather than 